\title{
On the Generative Condition of Undergraduates' Innovation Ability
}

\author{
Lin Ruijuan \\ School of English Language and Literature \\ Xi’an Fanyi University \\ Xi'an, P.R.China \\ e-mail: 354276603@qq.com
}

\begin{abstract}
Innovative ability is the core competitiveness of a country and a individual. It is an important mission of universities to build the "innovative nation" and to implement the strategy of "strengthening the nation with higher education", which is an important way for its development. In these conditions, the guide for them is the concept of innovation education; the key is for strengthening the construction of the faculty; the premise is to expand the knowledge base; the core is to enrich the practical aspects, the safeguard is to optimize the teaching evaluation. Though they are not sufficient conditions for the creation of innovative ability of undergraduates, only by strengthening the construction of these conditions is it possible to improve the innovative ability of undergraduates.
\end{abstract}

Keywords-Innovation Ability; Philosophy in Education; Teaching Evaluation

\section{INTRODUCTION}

With the era of knowledge-based economy, innovation has become an innovation becomes a buzzword. Competition between countries and enterprises is increasingly reflected in the competition between the state and the enterprises' innovation ability, and the competition among the individuals is more clearly manifested as the competition of innovation consciousness and innovation ability. Under the background of building "an innovative country" and "a strong power of higher education", colleges and universities should strengthen the cultivation of college students' innovative quality and put emphasis on the innovation ability of college students. As we know, the generative innovation ability of college students is not out of thin air, it needs a lot of important conditions to support.

\section{FORERUNNER: THE INNOVATION PHILOSOPHY IN EDUCATION}

"Education philosophy is to guide the educational ideas and spiritual pursuit. As long as the educational behavior occurs, there must be educational philosophy at work. As the education concept once formed, it will become a relatively stable spiritual power, it will affect a teacher how to understand the meaning of education, how to treat the relationship between teachers and students, how to deal with all kinds of contradictions in pedagogy."[1]The monopolistic characteristics of traditional Chinese culture represented by Confucianism and the changes of the education system based on political philosophy after the founding of China have formed and solidified the traditional education concept.
Under its influence, the atmosphere of innovation is always drifting away from the university campus. Maybe it is a little exaggerated to describe the college students' innovative spirit as repressive or suppressed, but at least it cannot be shaped and cultivated. Since the 1990s, the national authorities and universities have made a lot of efforts to formulate the relevant rules and regulations to standardize the personnel training in colleges and universities to achieve the purpose of improving the ability of college students, but it doesn't achieve the desired results. The reason is that the concept of innovative education is only a slogan, far from reality, so that these pedagogical documents lack the idea and concept to support. In other words, there is no compatibility between the tangible norms of formal institutions and the educational philosophy as an informal system.

Therefore, colleges and universities is to strengthen the leadership and investment of innovative education. As the Soviet educator Suhomlinski once said, "For the leadership of the school, the first is the ideological leadership, the executive, second." The university's historical mission and the ultimate goal of reform and development is to cultivate a large number of high-quality innovative talents, and cultivate students' innovative spirit and innovation ability as the focus, comprehensively promoting the quality education as the main content of pedagogical reform in the new century. Through various forms of innovative educational ideas to implement all aspects of school work, the faculty and students are aware of the importance of innovative educational philosophy. Only in this way will the university's various rules and regulations aim at promoting students' innovation.

\section{KEY: STRENGTHENING THE FACULTY'S CONSTRUCTION PREPARE YOUR PAPER BEFORE STYLING}

Mao Zedong once said: "For a school, the most important issue is the faculty and the education policy." Jiang Zemin also made it clear that it is fundamental for the construction of teachers. Hu Jintao at the meeting with the outstanding teacher representatives once put it, "To promote the cause of education and cultivate the high-quality talents, teachers are very important; there are no excellent teachers, and there is no high-quality education." Innovation of university students cannot be separated from the noble moral, profound knowledge, wisdom, teaching art. Chairman Xi Jinping also pointed out that it is very lucky for a person to own a good 
teacher in the life. For a university, it is a kind of glory; for a nation, hope and prosperity.

At present, the guidance of "scientific research" from the teacher evaluation system and the income distribution system in colleges and universities has the phenomenon of "teaching drift" which means "the scientific research overmatched the teaching". Apparently, many teachers will allocate more time and energy to the scientific research and do not want to teach students in the classroom, not to mention the reflection and improvement of teaching methods. So the students 'innovative ability training has not been paid much attention to by them. Giving full play to the role of teachers in the cultivation of students' innovative ability, we need to strengthen the construction of teachers to promote the professional development of teachers. To promote the professional development of teachers, it is necessary to improve the level of teachers' disciplines and more importantly, to enhance the teaching level and teaching wisdom.

First of all, to improve the teacher's education, teachers should learn through the theory of pedagogy, a profound understanding of the physical and mental development characteristics of college students and have good master of their growth and innovation ability to generate the teaching logic. Secondly, the important factor is to form the teachers' educational wisdom. Educational wisdom is a kind of action art, which is the art of transforming educational theory into teaching practice. Education wisdom can help teachers guide the teaching process well and more effectively when the students start dialogues and exchanges, which can stimulate the students' initiative and creativity. Last but not least is to develop the virtue of education. Pedagogy is a great cause full of noble virtue. For a teacher, the moral is the primary quality which determines the behavior of teachers and teaching direction. If a teacher loves the students with the whole heart, the teacher will build up the student-oriented teaching method and with greater enthusiasm and patience cultivate students' creative spirit.

\section{PRECONDITION: TO WIDEN THE BASIC KNOWLEDGE}

With the widespread use of electronic information technology and the popularity of the Internet, knowledge acquisition is more convenient than ever, and the ability to acquire knowledge and solve problems becomes more important, but this is not the reason of "contempt for knowledge" [2] because knowledge is the foundation of capacity development.

China's special incentive mechanism provided by the imperial examination system since the Sui and Tang dynasties not only affected the intellectual interest of intellectuals, but also had an important influence on the university education, which made the talented and curious genius confine the vision to the one-sided rigid text, and they are indifferent to the scientific revolution and innovation. This can explain "Joseph Needham mystery" - why the Chinese science and technology surpassed the other civilizations in the past, but now it is not the leading one in modern society. [3] After the founding of new China, the establishment of higher education follow the teaching style from Soviet Union. The professional division is not scientific which made the knowledge structure of college students "unscientific and narrow", they are regarded as the "screw" who lack of innovation and ability.

Knowledge has the characteristics of "time and space complementarity" [4], the wider the scope of knowledge is, the richer the structure of knowledge logic to get; the stronger the willingness and ability to acquire knowledge, the more solid the foundation of innovation and the more innovative space to get. Through the study of the history of foreign famous universities' teaching reform, we can easily find that they regard the general education as the basic work to improve students' innovation ability. Since the reform and opening up, with the development of higher education, too specialized issues have attracted increasing attention. At beginning of the late 1980s, strengthening the foundation, broadening the professional and discipline penetration have become the important part of higher education teaching reform. Many colleges and universities have made a lot of achievements in the personnel training objectives, general education and education programs, but there are also a lot of problems. The foundation of the development of innovative talents lies in the harmonious, comprehensive and free development of individuality. Therefore, in order to cultivate students' innovative ability, we should strive to establish a broad, logical rigorous curriculum system to achieve the balance between general education and professional education. The modern general education in American excellent universities aims to "form a common knowledge base for students to tap the common elements of human nature" which is highly successful in undergraduates' "common core curriculum". Therefore, the central task of general education in our country is to reorganize and promote the cultural traditions that we have broken since the Republic of China and the lack of logical rationality in Chinese traditional culture, and thus gradually formed our university's "Core curriculum" tradition. [5]

\section{CORE: ENRICHING THE LINK OF PRACTICE TEACHING}

As we know, many of the major discoveries of scientists are in practice to capture inspiration. Practice is a process which people used the knowledge to solve the problem. When solving the problem, people will find the gap of knowledge reserves and the individual will have a better grasp of the knowledge so that enrich the innovative knowledge base; when people cannot solve the current problem, the individual will put aside the preconceived to explore the new ideas and the new methods. All these constitute the basis of innovation and innovation of the basic schema.

In the long run, imparting knowledge is the main form of teaching, and knowledge acquisition is the main content of students' learning. However, the practical teaching and students' innovation in essence has been neglected for a long time. Students lost the basis of dynamic and basic conditions so that students' innovative spirit and ability are insufficient. Practical teaching is an important channel for cultivating students 'scientific outlook and viewpoints on life and values; it is also an important means for students to understand 
theoretical knowledge to form an active learning spirit and exercise comprehensive quality and ability. It is a way to cultivate students' theory and practice, and help them understand national conditions and be familiar with society so that improve the ideological and political quality and working proficiency; it is an important way to cultivate innovative talents.

In the process of the reform for teaching content, we should strengthen the practice teaching, specializing the content of the practice teaching, standardizing the teaching system, and construct the students' innovation ability as the core. Taking the basic practice, professional practice, comprehensive practice, innovation activity, and social activities five major platforms as the main content of the diversified practice teaching system.

Universities should strengthen the whole management of teaching practice, making it full of the time security, base security, and funding and system protection, giving full play to the guidance of teachers in the teaching practice to avoid the formalization, content devoid of innovation and disorder in teaching practice.

\section{SAFGUARD:OPTIMIZING TEACHING EVALUATION}

Teaching evaluation has a significant impact on teaching behavior, which helps teachers and students form the expectations of the future so as to encourage and constrain the activity between the teachers and the students in teaching - learning process. The evaluation guideline can show the teaching behavior. For example, if memorization and reproduction of the knowledge are regarded as the main content of the evaluation, then it is no wonder to see the subject-object relation between the teacher and student"duck-stuffing" type of teaching and one-sided teaching. Besides, if multimedia teaching can be seen as an important indicator of the effectiveness of classroom teaching, no one can deny that fact that the neglect of the training objectives and differences in teaching multimedia "idol" would occur.

At present, a large number of "teaching evaluation subject diversification" in the teaching evaluation are superficial, and the "teaching evaluation content are just a slogan; the form diversification of the teaching evaluation tended to be unrealistic. The cultivation of innovative quality of students in the context of the existing evaluation system has not been effectively motivated. Teaching evaluation depend on the teaching process and serves the training objectives. The innovative talents must be seen as the training objectives which require that the teaching evaluation should form a base on the students' innovation and innovative abilities.

First, the teaching evaluation of the main status in the students is important. Students are not only the subject of evaluation, because he is the participant and effect carrier of the teaching process, so the students have the right to speak of the teaching process, and the student's "schooling experience"[6] and the innovation appeal should be reflected in the teaching evaluation. Secondly, the full use of "non-test (traditional written test) assessment "should be paid attention to. Since the 80 s of last century, the single test method, the loose of the evaluation scale and the unhealthy atmosphere in examinations should be corrected" [7], the research reports, subject discussions, group debates, science and technology competitions can be used for the inspection of students' apprehension, ways of thinking, communications, manipulative ability, problem-solving skills and creativity. Third, to change the ultimate evaluation in the traditional teaching evaluation system is necessary. The formation of evaluation and diagnostic evaluation function are important and the unique roles of the formation of evaluation, diagnostic evaluation and the final evaluation of various evaluation forms should be attached importance to. Striving to achieve complementary advantages and discovering effectively the innovative potential of students are for the teaching process optimization to provide feedback.

\section{CONCLUSION}

The report of the 19th National Congress of the CPC clearly states: "After the long-term efforts, socialism with Chinese characteristics has entered a new era which is a brand-new historical position for our country's development." Colleges and universities should adhere to the guidance of socialism with Chinese characteristics in the new era as the guideline and grasp profoundly China's new historical position for the development, firmly establishing the development concept of innovation, coordination, greenness, openness and sharing, follows the law of the development of higher education and the law of cultivating all=round undergraduates, and endeavors to cultivate the innovative ability of undergraduates to meet the high demands of talents in the new era.

\section{REFERENCES}

[1] Gan Yang. The Idea, Goal and Model of Humanity Education. Peking University Education Review, 2006(3):38-65.

[2] Justin Yifu Lin. Needham Puzzle, Weber Question and China's Miracle: Long Term Performance Since the Song Dynasty. Journal of Peking University(Philosophy and Social Sciences), 2007(4): 5-22

[3] LengYusheng. On the Current Situation and Duty of Evaluation on the Higher Educational Quality from the Dispute of Quality. Journal of Higher Education, 2007(3):23-27.

[4] Wang Cesan. A Critical Reflection on the Thought of "Despising Knowledge". Peking University Education Review, 2004(3):5-23

[5] Wang Dingding. Knowledge's Complementarity with the Time and the Space and the Relative Economic. Economic Research Journal, 1997(6):70-78

[6] Yuan Zhenguo. New Idea of Education. Beijing: Education Science Press, 2002: foreword.

[7] Zhou Zuoyu, Zhou Yanyong. Students' Learning Experience: A New Perspective on the Evaluation of Higher Education. College (Study \& Evaluation), 2007(1):27-31. 